\title{
2006-2382: INDUSTRY-SPONSORED DESIGN COMPETITION: OPPORTUNITIES AND CHALLENGES FOR A CAPSTONE SENIOR DESIGN PROJECT
}

\author{
Betsy Aller, Western Michigan University \\ Dr. Betsy M. Aller has a Ph.D. and M.S in Rhetoric and Technical Communication from \\ Michigan Technological University. She coordinates senior capstone design and teaches technical \\ communication and industrial management courses in the Department of Industrial \& \\ Manufacturing Engineering at Western Michigan University. Dr. Aller's research interests \\ include professional development of students in the engineering workplace, assessment and \\ evaluation of ABET criterion and STEM-related experiences for women and minorities.
}

\section{Alamgir Choudhury, Western Michigan University}

Alamgir A. Choudhury is an assistant professor of industrial and manufacturing engineering at Western Michigan University, Kalamazoo, Michigan. He earned his MS and PhD from NMSU(Las Cruces) and BS in mechanical engineering from BUET (Dhaka). His interest includes computer applications in curriculum, MCAE, mechanics, fluid power and instrumentation \& process control. He is also a Registered Professional Engineer in the State of Ohio and affiliated with ASME, ASEE, SME and TAP.

\section{James Kamman, Western Michigan University}

Dr. James Kamman is an Associate Professor of Mechanical \& Aeronautical Engineering at Western Michigan University. He has Ph.D., M.S. and B.S. in Applied Mechanics from University of Cincinnati. Prior to working at WMU, Dr. Kamman developed computer models to test the open-loop and closed-loop performance of towed marine systems for the US Navy. He also designed and participated in at-sea, open-loop, and closed-loop performance tests of these systems. His research interest includes multibody system dynamics, numerical modeling and control.

\section{Jorge Rodriguez, Western Michigan University}

Jorge Rodriguez is an Associate Professor in the Department of Industrial and Manufacturing Engineering and a Research Associate of the Human Performance Institute at Western Michigan University. He received his Ph.D. in Mechanical Engineering from University of Wisconsin-Madison and his M.B.A. from Rutgers University in Piscataway, NJ. Dr. Rodriguez teaches courses in Computer-Aided Design and Manufacturing, Mechanical Design, Biomechanics and Finite Element Analysis. His research is in the field of computers in engineering, particularly in machine design, systems modeling, and biomechanics.

\section{Mohammed Elsamawal, Western Michigan University}

Mohammed Elsamawal is a graduate student in the Department of Industrial and Manufacturing Engineering at Western Michigan University. He received his BS in mechanical engineering from Omdurman Islamic University and currently pursuing a Masters in Manufacturing Engineering. His proficiency is in machine shop fabrication and maintenance of tractor and automotive system.

\section{Michael Desjardins, Western Michigan University}

Michael Desjardins is an undergraduate student of Engineering Graphics and Design Technology at Western Michigan University. He was a team member of the hydraulic bicycle design project and represented Western Michigan University in Parker Chainless Challenge in 2005. Currently he is working as a design engineer with Mann+Hummel in Kalamazoo, MI. He is proficient in IDEAS, Pro-E and CATIA for design and analysis. 


\title{
Industry-sponsored Design Competition: Opportunities and Challenges for a Capstone Senior Design Project
}

\begin{abstract}
Industry-sponsored product development competitions pose both opportunities and challenges for senior design projects in engineering and engineering technology programs. Capstone design faculty recognize the value of industry-sponsored projects for involving students in genuine practice of the design process, and participating in major competitions can result in substantial resources, supportive sponsors, and enhanced motivation for students. However, such competitions may also impose timing, process, materials, fabrication, and performance constraints that are not always encountered in a more typical capstone design project. This paper discusses a Western Michigan University senior design project that was part of a national hydraulic bicycle design competition sponsored by Parker Hannifin Corporation. Innovative product design based on specified design criteria led students through each step of a complete design process, and the design project eventual ranking in the national competition. Incorporating long-term performance criteria of a product at an early stage of the design cycle was beneficial, and this experience is discussed. However, the team encountered a number of challenges in working through the many constraints of the competition. Because such competitions typically work from a corporate rather than an academic timeline, prototyping, design refinement, fabrication of the final product, and a performance-based competition may be overwhelming for a two-semester project. Variability of the design team, integration of multiple design concepts in the final design, component fabrication, and performance issues related to selection of available industrial components in lieu of specified components in the design are also discussed. All of these specific conditions affect the implementation method of a traditional engineering design process and must be addressed by senior design faculty. Thus, while industry-sponsored competitions offer exciting potential for capstone design projects, it is important that faculty, students, and sponsors recognize and respond to the constraints and challenges they are likely to face in successful completion of these projects.
\end{abstract}

\section{Introduction}

Capstone design faculty increasingly seeks corporate sponsorship and involvement in senior projects, recognizing the value for students in responding to "real-world" needs, expectations, and constraints ${ }^{1}$. Motivation for students is enhanced when they see themselves solving a genuine problem for a real client ${ }^{2,3}$, and interaction with sponsors exposes students to demands and requirements not typically encountered in usual lab settings. Both this motivation and the rigor of project requirements can be heightened when the industry-based senior project is part of a larger competition ${ }^{4}$. This paper discusses one such project, undertaken for Parker Hannifin Corporation's national competition for design of a hydraulic bicycle by a senior team of four 
students from the Industrial and Manufacturing Engineering (IME) department of Western Michigan University (WMU).

\section{Senior Capstone Design Initiation}

The capstone senior design project in Western Michigan's IME department is typically a twosemester project. Early in the first semester, department faculty present potential projects - some with industry sponsors, some based on grant research - to students enrolled in a Senior Design Proposal class. After all projects have been presented, students bid on their preferred project, and teams of three or four are formed. This team-based course design trend reflects industry practice, where teamwork has become the prevalent mode ${ }^{5}$. During this bidding process, students are required to seek out the faculty who presented the project, with the goal of both learning more about the project and allowing the faculty to get a sense of the best team for the project. The course coordinator encourages students to ask faculty advisors questions about project timing, budget, potential funding, objectives, etc. In the case where the project has an industry sponsor, be that for commercial purposes or for non-for-profit organization, students are urged to ask about sponsor expectations, additional or unusual time lines, and specific design constraints. Naturally, not all of these questions can be answered at this stage, resulting in occasional frustration, but learning to ask the right questions is integral to the design process ${ }^{6}$.

The Parker Hannifin hydraulic bicycle project was presented to the class in the usual manner, along with a number of other projects that fall 2004 semester. The faculty advisor noted that the competition would take place in summer of 2005, after most of the students would have graduated. Subsequent class discussions showed that students thought this project very intriguing and were excited, but also cautious, about the possibility of being involved in a national competition. After the bidding process was completed, a group of four students - two engineering graphics and design technology majors and two manufacturing engineering technology majors - received the hydraulic bicycle design as their senior project.

The project team then began the typical process of defining the project, researching necessary background information, articulating a plan to solve the problem, writing an official proposal, undertaking the appropriate tasks, testing, evaluating, refining, and finally, reporting findings and making recommendations ${ }^{7,8}$. Along the way, this industry-sponsored team, working under the specific needs of the competition, encountered and ultimately worked through a number of constraints and expectations most of their classmates did not experience.

\section{Design Objectives}

The main objective of the hydraulic bicycle project was innovative design of a safe one person bicycle that will use a rider's manual power to drive the bike without the use of chain or mechanical link. The bicycle must have multiple, fully active, independent brakes that provide a 
failsafe braking condition. Additionally, the rider must be able to enter, exit, start and stop the bike unassisted.

\section{Project Planning}

In the College of Engineering Applied Sciences (CEAS) of WMU, senior design projects require that from the initial introduction to final presentation, students must complete all tasks for design, fabrication, documentation, and presentation of the project within a period of two semesters. Therefore, to ensure that all project objectives are achieved in a timely fashion, students are guided to prepare a detailed plan of the overall project right after selection of the projects and respective design groups. This is especially important for industry sponsored projects where additional external constraint adds to the complexity of the project. In the $5^{\text {th }}$ week of the Fall semester, the hydraulic bicycle team identified the tasks to achieve the design objectives in a total of twenty six weeks. Overall tasks were: literature search, brainstorming and concept generation, analysis and feasibility of different concepts, selection of design concept, detail system design, analysis of components and system, optimization and refinement of system, CAD model and design specification, prototype fabrication, testing and evaluation, and final project reporting at the end of the Spring semester. It was intended that in the begining of summer semester, the student team would further refine design and fabricate the overall system during the summer semester.

\section{Design Methodology}

From the begining, the focus of this design was to develop a hydrualic circuit that would allow transfer of rider's power to the driving wheel in a controlled fashion. The circuit should be able to store graviational energy during a down hill journy and utilize the stored energy later to propel the bike to the up hill slope. Rest of the system would be designed to accomodate this circuit in a recumbent bicycle frame. Therefore, the design task was separated as circuit design and component specification based on its performance requirement.

\section{Design of Hydraulic Circuit}

The main focus of this project is the design of a hydraulic circuit that will successfully transfer the energy produced by the rider into the motion of the bicycle or store that energy to be used as needed. To accomplish the performance objectives of this circuit, there was brainstorming sessions held where ideas and concepts leading to our final results where discussed. After the completion of the brainstorming sessions, each project member designed two hydraulic circuits that meet the desired needs. Once these individual designs had been completed they were developed and tested using Automation Studio ${ }^{7}$. With this final circuit design concept, all system requirements were then calculated therefore, refining and maximizing the efficiency of the system. After completing the design of the hydraulic circuit (Figure 1), components were specified that met the design requirements. The hydraulic circuit was assembled in the laboratory 
and its performance was tested (Figure 2). After fine-tuning the circuit for improving its performance, a complete 3-D CAD layout of the hydraulic circuit was developed using ProEngineer ${ }^{8}$.

\section{Design of Bicycle Frame}

After completion of the hydraulic circuit design, a recumbent frame was chosen for the system as opposed to designing and fabricating the frame from scratch. This allowed the group to focus on spefication of rest of the components and system assembly and manufacturability. A second brainstorming session was used to develop ideas and concepts on component layout on the frame. To ensure the integrity of the overall system prior to fabrication, an assembly model of the frame along with the componets was developed in Pro-Engineer, and stress and deformation analysis was performed using $\mathrm{ANSYS}^{9}$ finite element package.

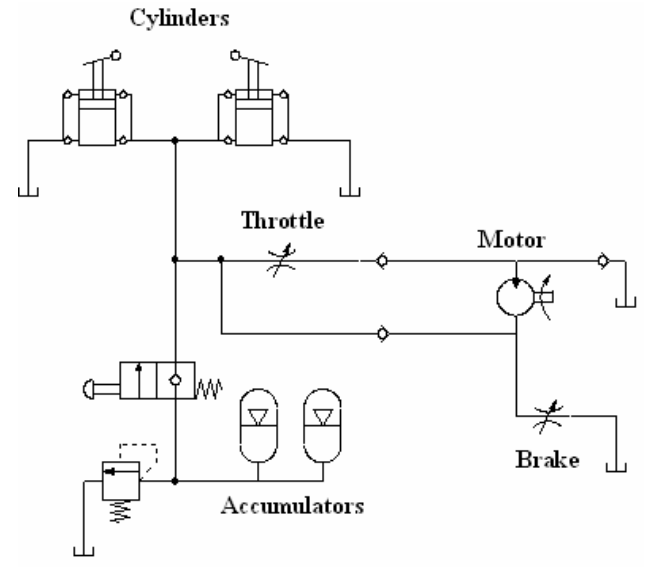

Figure 1. A prototype hydraulic circuit

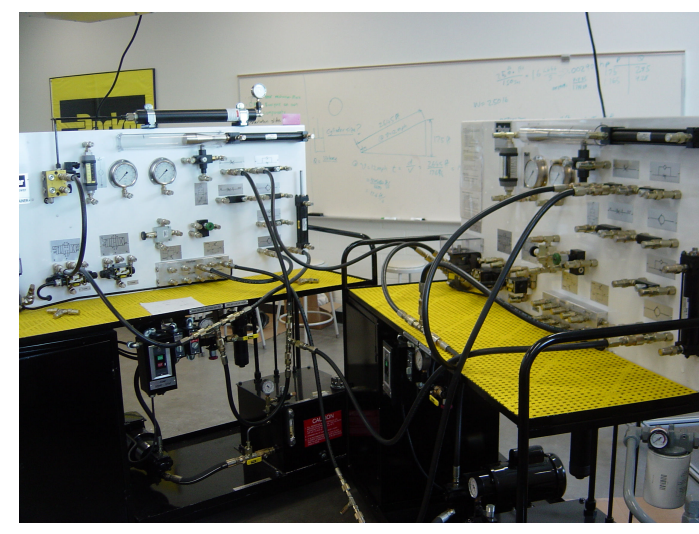

Figure 2. Hydraulic circuit test setup

\section{Component Specifications and Project Presentation}

The requirements for this system were calculated based on performance criteria specified by Parker Hannifin Corporation. Figure 3 shows the track elevation for the competition which includes total track lenght of 12 miles with a slope of up to $3.79^{\circ}$. The compoents were specified based on the velocity, weight, adn energy storage capacity of the system. According to the requirement of the senior design project, a stationary model of the functional prototype was developed as proof of concept and demonstrated during final presentation of project. 

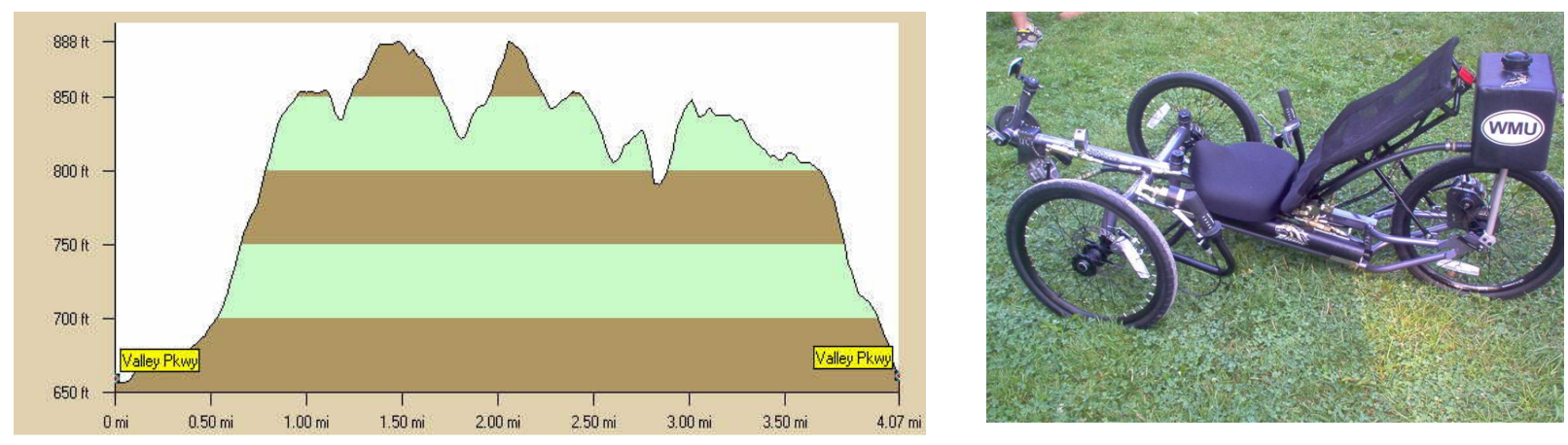

Figure 3. Track Elevation and fabricated model

\section{Fabrication of Bicycle}

Considering availability of components in the market and feasibility of the fabrication methods recommended in the design, at the end of the Spring semester, the group re-evaluated their design. The hydraulic cylinders were replaced by a hydraulic motor and components were respecified based on performance characteristics of the motor and available industrial hydraulic components. The foremost problem encountered was, no hydraulic motor was available that would provide a variable torque and rpm according as required by the bicycle from starting to final position in an actual ride. Therefore the design settled with input and output gear ratios which would suit the requirement of the hydraulic circuit in relatively slow motion. As a result the performance of the bike was compromised. The final system was composed of frame and components purchased from market. The total cost for this hydraulic bicycle without considering the fabrication cost came to $\$ 2,931.42$.

\section{Senior Design and Parker Chainless Challenge}

The bicycle entered a performance competion with designs from ten other universities during the summer. The purpose of the competition was to challenge undergraduate engineering and engineering technology students for innovative design and development of a bicycle that would transfer a rider's manual power to the driving wheel through the use of a hydraulic media. Parker provided monetary and material grant to each university to offset the cost of design and fabrication of the system.

It was an exciting demonstration of a wide variety of designs from nine different universities. Each participating university brought its system and competed in a 12-mile speed circuit and a 300-ft. sprint circuit. The designs were evaluated by Parker judges and ranked based their performance in the circuit races, novelty in engineering design, reliability and safety, manufacturability, marketability, cost, workmanship, and design report. The event was covered by local television media and Cleveland Plain Dealer. The design competition also appeared in the October issue of the Machine Design Magazine ${ }^{10}$. Parker considered the event a resounding 
success and plans to continue the competition during the year 2005-06. Considering the performance of each design team, Parker has provided additional guidlines for the future competion. At WMU, a new senior design team has entered in a new design project to overcome the diffculties encountered by the current design.

\section{Observation}

After graduation of the WMU senior design group, a new team was formed to further improve the design, fabricate the bicycle and participate in the performance competition. The competion was treated as an extension of the regular capstone design project. It was noticed that other participating schools organized their student teams in a diverse way. Several universities planned multiyear hydraulic bicycle projects engaging students from freshman to senior levels. Their objective is to produce award winning designs each year. Obviously a mechanism needs to be in place to guide their senior design project from begining to end and allow completion of the capstone design project independent of overall bicycle project. Apparently the seniors were benifited by exposure to issues related to social and team dynamics while completing their technical tasks. But such interaction may also hinder execution of a complete project from concept through final performance testing of a functional model. On the other hand blending of institutional pride with participation in such projects motivates excellence in student performance.

\section{Project Outcomes and Benefits}

The student team's participation and success in this national competition received much attention by university and local news agencies. Articles appeared in news releases and newsletters at the university, college, and department level, and project leaders were sought out for comments and advice. The university provost included the competition in her newsletter, and the dean of the College of Engineering and Applied Sciences singled out the project in his "back to school" address in fall 2005.

But beyond the immediate positive attention were longer-lasting benefits. All of the undergraduate students involved in this project included a section on their resumes with specifics of the hydraulic bicycle project goals, design tasks undertaken, and final accomplishments, including the ranking in the national competition. These students report that potential employer interest has been strong; this section on the resume has inevitably sparked conversation with interviewers and has even been instrumental in job offers. Furthermore, current and, future senior design students are extremely interested in similar project and its success. The course coordinator uses this project as an example of a rigorous senior design experience, with all the frustrations and occasional setbacks typical of industry projects, but with all the positive outcomes associated with perseverance, growing understanding, and commitment ${ }^{12,13}$. Given these outcomes, there is something more to be said about competition-based projects over some 
of the other projects, and that is the additional motivation and perseverance that the team needs to show and apply. Particularly taking into consideration that during the same cycle of senior design projects there were also a service-learning project (for a non-for-profit organization) and couple of commercial industry-based projects. Compared to other traditional capstone design project, a different execution plan would be necessary for industry sponsored design competition projects.

\section{References}

1. National Research Council, Engineering education: Designing an adaptive system, Washington, D.C.: National Academy Press, 1995.

2. National Academy of Engineering, http://www.nae.edu/nae/caseecomnew.nsf?OpenDatabase, 14 January 2006,

3. Commission on Behavioral and Social Sciences and Education. 2000. How people learn: Brain, mind, experience, and school: Expanded edition. The National Academies Press.

4. Blust, R. And Myszka, D., Merging Design Competition and Industry Sponsored Projects, Proceedings of ASEE Annual Conference and Exhibition, 2005.

5. Shuman, L.J., Besterfield-Sacre, M., McGourty, J., The ABET "professional skills" - can they be taught? Can they be assessed? Journal of Engineering Education, Jan. 2005.

6. Holtzapple, M.T., and Reece, W.D. 2005. Concepts in engineering. Boston: McGraw Hill.

7. Peters, M.S., Timmerhaus, K.D., and West, R.E. Plant design and economics for chemical engineers, 5th edition. 2003. Boston: McGraw Hill.

8. Automation Studio, http://www.automationstudio.com

9. Pro-Engineer, $\underline{\text { http://www.ptc.com }}$

10. ANSYS, http://www.ansys.com

11. Machine Design, www.machinedesign.com

12. Lamancusa, J., Soyster, A., and George, R., Industry-Based Projects in Academia - What Works and What Doesn't, Proceedings of ASEE Annual Conference and Exhibition, 1997.

13. Peterson, J. N., Experiences in Capstone Design Projects: Partnership with Industrial Sponsors, Proceedings of ASEE Annual Conference and Exhibition, 2004.

14. Bullard, L.G., Clayton, P. H and Peretti, S. W., Service-learning in CHE Senior Design, Proceedings of ASEE Annual Conference and Exhibition, 2004. 